\title{
Parasitism and migration in southern Palaearctic populations of the painted lady butterfly, Vanessa cardui (Lepidoptera: Nymphalidae)
}

\author{
CONSTANTí STEFANESCU ${ }^{1,2}$, Richard R. ASKEW ${ }^{3}$, Jordi CORBERA ${ }^{4}$ and Mark R. SHAW ${ }^{5}$ \\ ${ }^{1}$ Butterfly Monitoring Scheme, Museu de Granollers-Ciències Naturals, Francesc Macià, 51, Granollers, E-08402, Spain; \\ e-mail: canliro@gmail.com \\ ${ }^{2}$ Global Ecology Unit, CREAF-CEAB-CSIC, Edifici C, Campus de Bellaterra, Bellaterra, E-08193, Spain \\ ${ }^{3}$ Beeston Hall Mews, Tarporley, Cheshire, CW6 9TZ, England, UK \\ ${ }^{4}$ Secció de Ciències Naturals, Museu de Mataró, El Carreró 17-19, Mataró, E-08301, Spain \\ ${ }^{5}$ Honorary Research Associate, National Museums of Scotland, Scotland, UK
}

\begin{abstract}
Key words. Lepidoptera, Nymphalidae, population dynamics, seasonal migration, enemy-free space, primary parasitoids, Cotesia
\end{abstract} vanessae, secondary parasitoids

\begin{abstract}
The painted lady butterfly (Vanessa cardui) (Lepidoptera: Nymphalidae: Nymphalinae) is well known for its seasonal long-distance migrations and for its dramatic population fluctuations between years. Although parasitism has occasionally been noted as an important mortality factor for this butterfly, no comprehensive study has quantified and compared its parasitoid complexes in different geographical areas or seasons. In 2009, a year when this butterfly was extraordinarily abundant in the western Palaearctic, we assessed the spatial and temporal variation in larval parasitism in central Morocco (late winter and autumn) and north-east Spain (spring and late summer). The primary parasitoids in the complexes comprised a few relatively specialized koinobionts that are a regular and important mortality factor in the host populations. However, there was a strong seasonal variation in the level of parasitism. In Spain percentage parasitism was more than four times higher in late summer than in spring $(77.3 \%$ vs. $18 \%)$, while in Morocco it was five times higher by the end of winter than in the autumn (66.2\% vs. $13.2 \%)$. In both regions the build up of parasitoid populations occurred after $V$. cardui had bred in the same general area over successive generations, and this may represent a selective force favouring seasonal migration to enemy-free space.
\end{abstract}

\section{INTRODUCTION}

A recent review of parasitism of European butterflies clearly revealed a paucity of comprehensive studies dealing with the parasitoid complexes of species in this popular taxonomic group (Shaw et al., 2009). Not only have very few species been studied in detail but, whenever this has been accomplished, sampling has been conducted in only one or a few areas. In consequence, there is a dearth of information on both the impact of parasitoids on butterfly populations and the changing structure of parasitoid assemblages across geographical ranges.

Quite surprisingly, this lack of information applies even to some of the most common butterflies, such as the painted lady, Vanessa cardui (Linnaeus, 1758) (Lepidoptera: Nymphalidae: Nymphalinae). Although the relative ease with which painted lady eggs and larvae may be found, coupled with their occasional abundance following episodes of massive migration, has led to a number of records of parasitism, no attempt has ever been made to quantify and compare the parasitoid complexes in different geographical areas or seasons. In spite of this, there is circumstantial evidence that parasitism can be an important mortality factor and it has been suggested that long distance migration in this butterfly has evolved partly to reduce parasitoid load (Owen, 1987).

The painted lady is well known for its remarkable migratory behaviour and for its dramatic population fluc- tuations between years (Williams, 1970; Pollard et al., 1998; Vandenbosch, 2003). In West Africa and the western Palaearctic, migrations occur between the Sahel (the region of western Africa between the Sahara Desert and the Gulf of Guinea), North Africa (e.g. several areas in the Maghreb and the Canary Islands), the Mediterranean Basin and central and northern Europe in a succession of generations, allowing the species to exploit abundant but ephemeral resources that shift latitudinally as the seasons progress (Stefanescu et al., in prep.). Although years of exceptional painted lady abundance in Europe have been documented (e.g. Williams, 1930, 1970), the migration of 2009 was certainly one of the most impressive ever recorded, and the strongest since regular butterfly monitoring began on the continent in the early 1970s. Huge numbers of adults were recorded from southern Morocco to northern Europe and, occasionally, mass concentrations of larvae were also found (Fox, 2010; Stefanescu et al., 2011). This provided a unique opportunity to adequately sample immature stages and the corresponding parasitoid complexes across a wide latitudinal range.

In this study we focus on parasitism of $V$. cardui in central Morocco and north-east Spain, two key regions within the migratory system connecting Africa and Europe. Specifically, we were interested in assessing the spatial and temporal variation in the parasitoid assem- 
blages attacking different generations of the butterfly. We begin by describing the size (i.e. the number of parasitoid species recorded from the host, and of secondary parasitoids from one of the main primary parasitoids) and composition of the parasitoid assemblage (i.e. the taxonomy and ecology of these parasitoids), as well as the level of parasitoids on the host populations in the two study areas, and how these vary through the year. The results are then discussed in the context of earlier work on global patterns in host-parasitoid interactions, as for example the reported increasing levels of parasitism in populations of multivoltine hosts in succeeding generations (e.g. Dempster, 1984; Askew \& Shaw, 1986) and the advantages of seasonal migration as a way to reduce parasitoid load by colonizing new habitats that may temporarily provide enemy-free space (Jeffries \& Lawton, 1984).

\section{MATERIAL AND METHODS}

\section{Study species}

Vanessa cardui is probably the most cosmopolitan of all butterflies, being present in all continents except South America and Antarctica (Shields, 1992). It is extremely polyphagous and many foodplants belonging to a number of plant families are used across its range (Ackery, 1988). However, in the western Palaearctic, oviposition occurs mostly on thistles (species in the tribe Cardueae, family Asteraceae) and common mallow, Malva sylvestris (Linnaeus, 1753) (family Malvaceae), growing in ruderal habitats (e.g. Stefanescu, 1997; Asher et al., 2001; Stefanescu et al., 2011). Eggs are laid singly on the foodplants, on which larvae will live within characteristic silken tents. When fully developed, the larvae leave the plant in search of a suitable pupation site. Developmental time has been estimated at 5 days for the egg, 25 days for the five larval instars and 14 days for the pupa in Egypt (Hammad \& Raafat, 1972). The completion of the whole cycle takes normally six to eight weeks, depending on environmental conditions.

$V$. cardui is a continuously-brooded species in which migration is used as an alternative to diapause as a means of surviving climatic extremes (Wiltshire, 1949). Each year, it colonizes the European continent from its African overwintering quarters in a northward spread comprising two successive generations (Stefanescu et al., in prep.). In the Mediterranean region, migrants are normally first recorded in April. It is mainly their progeny that colonize central and northern Europe at the end of May and in June. Butterflies emerging after mid summer will then start moving south in a return flight (Stefanescu et al., in prep.). Available data suggest that most butterflies head directly to Africa, although some individuals will stop for breeding in central and southern Europe to complete additional summer generations (Stefanescu et al., in prep.). From September-October to March-April, V. cardui is recorded continuously in North Africa and the Canary Islands, although local movements within this region may occur throughout the winter (e.g. Wiemers, 1995)

\section{Study areas and sampling of parasitoids}

The study was undertaken in 2009 in two large areas in central-western Morocco (between latitudes $29^{\circ} 90^{\prime}-31^{\circ} 60^{\prime} \mathrm{N}$ and longitudes $5^{\circ} 20^{\prime}-9^{\circ} 60^{\prime} \mathrm{W}$ ) and north-east Spain (between latitudes $41^{\circ} 60^{\prime}-42^{\circ} 75^{\prime} \mathrm{N}$ and longitudes $\left.0^{\circ} 35^{\prime} \mathrm{W}-2^{\circ} 50^{\prime} \mathrm{E}\right)$. Larval (in which we include larval-pupal) parasitism was assessed for the first and last generations occurring annually in both regions. In Morocco, sampling was carried out from 26 to 30 March, and from 19 October to 15 November; in Spain, from
TABLE 1. Locations in north-east Spain (spring and late summer) and Morocco (late winter and autumn) surveyed for Vanessa cardui immatures in 2009.

\begin{tabular}{|c|c|c|c|}
\hline Study site & Latitude & Longitude & Date \\
\hline \multicolumn{4}{|l|}{ NE Spain - spring } \\
\hline Sorteny (Pyrenees) & $42.61^{\circ} \mathrm{N}$ & $1.57^{\circ} \mathrm{E}$ & 27 Jun 2009 \\
\hline S Celoni & $41.67^{\circ} \mathrm{N}$ & $2.47^{\circ} \mathrm{E}$ & 26 May 2009 \\
\hline S P Vilamajor_1 & $41.68^{\circ} \mathrm{N}$ & $2.39^{\circ} \mathrm{E}$ & 31 May 2009 \\
\hline S P Vilamajor_2 & $41.68^{\circ} \mathrm{N}$ & $2.39^{\circ} \mathrm{E}$ & 06 Jun 2009 \\
\hline \multicolumn{4}{|l|}{ NE Spain - late summer } \\
\hline Marialles (Pyrenees) & $42.53^{\circ} \mathrm{N}$ & $2.41^{\circ} \mathrm{E}$ & 06 Aug 2009 \\
\hline Peña Telera (Pyrenees) & $42.72^{\circ} \mathrm{N}$ & $0.35^{\circ} \mathrm{W}$ & 01 Sep 2009 \\
\hline Nevà (Pyrenees) & $42.30^{\circ} \mathrm{N}$ & $2.06^{\circ} \mathrm{E}$ & 24 Aug 2009 \\
\hline S A Vilamajor & $41.69^{\circ} \mathrm{N}$ & $2.40^{\circ} \mathrm{E}$ & 10 Oct 2009 \\
\hline S P Vilamajor_1 & $41.68^{\circ} \mathrm{N}$ & $2.39^{\circ} \mathrm{E}$ & 27 Sep 2009 \\
\hline S P Vilamajor_2 & $41.68^{\circ} \mathrm{N}$ & $2.39^{\circ} \mathrm{E}$ & 05 Oct 2009 \\
\hline \multicolumn{4}{|l|}{ Morocco - late winter } \\
\hline P9 & $31.45^{\circ} \mathrm{N}$ & $5.34^{\circ} \mathrm{W}$ & 26 Mar 2009 \\
\hline $\mathrm{P} 10$ & $31.44^{\circ} \mathrm{N}$ & $5.34^{\circ} \mathrm{W}$ & 26 Mar 2009 \\
\hline P11 & $31.14^{\circ} \mathrm{N}$ & $5.20^{\circ} \mathrm{W}$ & 26 Mar 2009 \\
\hline $\mathrm{P} 13$ & $30.79^{\circ} \mathrm{N}$ & $5.52^{\circ} \mathrm{W}$ & 26 Mar 2009 \\
\hline P14 & $30.79^{\circ} \mathrm{N}$ & $5.58^{\circ} \mathrm{W}$ & 26 Mar 2009 \\
\hline $\mathrm{P} 15$ & $30.66^{\circ} \mathrm{N}$ & $6.56^{\circ} \mathrm{W}$ & 27 Mar 2009 \\
\hline P16 & $30.53^{\circ} \mathrm{N}$ & $6.90^{\circ} \mathrm{W}$ & 27 Mar 2009 \\
\hline $\mathrm{P} 20$ & $30.52^{\circ} \mathrm{N}$ & $7.91^{\circ} \mathrm{W}$ & 27 Mar 2009 \\
\hline $\mathrm{P} 22$ & $30.49^{\circ} \mathrm{N}$ & $8.75^{\circ} \mathrm{W}$ & 28 Mar 2009 \\
\hline $\mathrm{P} 23$ & $30.49^{\circ} \mathrm{N}$ & $8.79^{\circ} \mathrm{W}$ & 28 Mar 2009 \\
\hline P24 & $30.49^{\circ} \mathrm{N}$ & $8.85^{\circ} \mathrm{W}$ & 28 Mar 2009 \\
\hline P27 & $30.06^{\circ} \mathrm{N}$ & $9.07^{\circ} \mathrm{W}$ & 29 Mar 2009 \\
\hline P28 & $29.99^{\circ} \mathrm{N}$ & $9.03^{\circ} \mathrm{W}$ & 29 Mar 2009 \\
\hline $\mathrm{P} 31$ & $30.17^{\circ} \mathrm{N}$ & $9.25^{\circ} \mathrm{W}$ & 30 Mar 2009 \\
\hline P34 & $31.58^{\circ} \mathrm{N}$ & $8.58^{\circ} \mathrm{W}$ & 30 Mar 2009 \\
\hline \multicolumn{4}{|l|}{ Morocco - autumn } \\
\hline P0_1 & $31.51^{\circ} \mathrm{N}$ & $7.21^{\circ} \mathrm{W}$ & 19 Oct 2009 \\
\hline $\mathrm{P} 0 \_2$ & $31.51^{\circ} \mathrm{N}$ & $7.21^{\circ} \mathrm{W}$ & 15 Nov 2009 \\
\hline P1_1 & $31.05^{\circ} \mathrm{N}$ & $7.13^{\circ} \mathrm{W}$ & 20 Oct 2009 \\
\hline $\mathrm{P}-2$ & $31.05^{\circ} \mathrm{N}$ & $7.13^{\circ} \mathrm{W}$ & 23 Oct 2009 \\
\hline$\overline{\mathrm{P} 2}$ & $31.44^{\circ} \mathrm{N}$ & $5.99^{\circ} \mathrm{W}$ & 20 Oct 2009 \\
\hline P3 & $31.26^{\circ} \mathrm{N}$ & $6.07^{\circ} \mathrm{W}$ & 20 Oct 2009 \\
\hline P5 & $30.87^{\circ} \mathrm{N}$ & $6.88^{\circ} \mathrm{W}$ & 21 Oct 2009 \\
\hline P7 & $30.70^{\circ} \mathrm{N}$ & $6.25^{\circ} \mathrm{W}$ & 21 Oct 2009 \\
\hline P11 & $30.57^{\circ} \mathrm{N}$ & $6.74^{\circ} \mathrm{W}$ & 26 Oct 2009 \\
\hline P15 & $29.91^{\circ} \mathrm{N}$ & $8.53^{\circ} \mathrm{W}$ & 27 Oct 2009 \\
\hline P17 & $30.47^{\circ} \mathrm{N}$ & $8.87^{\circ} \mathrm{W}$ & 28 Oct 2009 \\
\hline P18 & $30.43^{\circ} \mathrm{N}$ & $9.58^{\circ} \mathrm{W}$ & 29 Oct 2009 \\
\hline
\end{tabular}

26 May to 27 June, and from 6 August to 10 October (Table 1). Larvae were intensively searched for at sites with suitable foodplants (M. sylvestris and several species of thistles, both in north-east Spain and Morocco), and caterpillars of any instar were collected and reared until they produced either parasitoids or adult butterflies.

In addition, pupal parasitism and secondary parasitism were studied at one mass emergence site in Morocco (site P24 in Table 1) in March 2009, where in a well delimited 1.8 ha area of wasteland, near Taroudant, adults were emerging from an abundance of pupae hanging from low vegetation (see Stefanescu et al., 2011, for details). Pupal parasitism was assessed by collecting, and rearing in the laboratory, a random sample of 50 pupae. A large number of cocoon clusters of the gregarious larval parasitoid Cotesia vanessae (Hymenoptera: Braconidae: Microgastrinae) were also present at the site. A sample of 100 cocoon 
TABLE 2. Species of primary and secondary parasitoids of Vanessa cardui reared during the course of this study.

\begin{tabular}{|c|c|c|c|}
\hline & Family & Subfamily & Trophic relationship \\
\hline \multicolumn{4}{|l|}{ HYMENOPTERA: ICHNEUMONOIDEA } \\
\hline Thyrateles camelinus (Wesmael, 1845) & Ichneumonidae & Ichneumoninae & primary parasitoid \\
\hline Itoplectis maculator (Fabricius, 1775) & Ichneumonidae & Pimplinae & secondary parasitoid \\
\hline Lysibia nanus (Gravenhorst, 1829) & Ichneumonidae & Cryptinae & secondary parasitoid \\
\hline Gelis sp. & Ichneumonidae & Cryptinae & secondary parasitoid \\
\hline Campoplegine sp. indet. & Ichneumonidae & Campopleginae & primary parasitoid \\
\hline Cotesia vanessae (Reinhard, 1880) & Braconidae & Microgastrinae & primary parasitoid \\
\hline Cotesia vestalis (Haliday, 1834) & Braconidae & Microgastrinae & primary parasitoid \\
\hline Dolichogenidea sicaria (Marshall, 1885) & Braconidae & Microgastrinae & primary parasitoid \\
\hline Microgastrine sp. indet. & Braconidae & Microgastrinae & primary parasitoid \\
\hline \multicolumn{4}{|l|}{ HyMenoptera: Chalcidoidea } \\
\hline Belaspidia obscura Masi, 1916 & Chalcididae & Haltichellinae & secondary parasitoid \\
\hline Catolaccus crassiceps (Masi, 1911) & Pteromalidae & Pteromalinae & secondary parasitoid \\
\hline Pteromalus puparum (Linnaeus, 1758) & Pteromalidae & Pteromalinae & primary parasitoid \\
\hline Pteromalus semotus (Walker, 1834) & Pteromalidae & Pteromalinae & secondary parasitoid \\
\hline \multicolumn{4}{|l|}{ DIPTERA } \\
\hline Exorista segregata (Rondani, 1859) & Tachinidae & Exoristinae & primary parasitoid \\
\hline Sturmia bella (Meigen, 1824) & Tachinidae & Exoristinae & primary parasitoid \\
\hline
\end{tabular}

clusters were kept individually in plastic vials and used for estimating the incidence of secondary parasitoids in the primary parasitoid population, as well as possible interactions between them (e.g. tertiary parasitism). Another sample of 50 cocoon clusters was held in a few larger plastic containers, and the reared secondary parasitoids were used to further assess the general abundance and sex ratios of individual species. Nine cocoon clusters of $C$. vanessae were also collected from two other sites to complement our data on secondary parasitism.

We appreciate that percentage parasitism within samples will not accurately reflect overall generational percentage mortality due to parasitism (Shaw et al., 2009), but these percentages are considered to be valid as a means of comparing samples in the context of this study.

\section{RESULTS}

A taxonomic list of the 15 primary and secondary parasitoids of $V$. cardui that were reared during the course of this study is given in Table 2, and the main species together with their general impact on the host populations are depicted in Fig. 1.

\section{Primary parasitoids of Vanessa cardui}

\section{Larval parasitism in Spain}

One hundred and fifty one larvae were sampled in north-east Spain (Table 3a). This sample comprised the progeny of African spring migrants (128 larvae) and late summer butterflies from Europe (23 larvae), but a few larvae died from unknown causes during the rearing process, thereby reducing effective sample sizes to 111 and 22 larvae in these two groups, respectively. Overall, six species of primary parasitoids were recorded, three larval and three larval-pupal parasitoids (Fig. 1). Of these, the tachinid Exorista segregata, a common polyphagous species, was reared only once in spring and can be considered an unimportant parasitoid of $V$. cardui in this region.

Percentage parasitism in the samples was more than four times higher in late summer $(77.3 \%)$ than in spring (18\%) (Fig. 2, Table 3a). This difference was due to the much higher incidence of the tachinid Sturmia bella
(36.4\% parasitism in late summer, compared to $7.2 \%$ in spring), and also to three microgastrine larval parasitoids (Cotesia vanessae, Cotesia vestalis $(=C$. plutellae (Kurdjumov, 1912)) and Dolichogenidea sicaria) that each killed $\sim 10 \%$ of the larvae in late summer but were absent in spring. The ichneumonine larval-pupal parasitoid Thyrateles camelinus appeared in spring and also late summer, killing $\sim 10 \%$ of the reared larvae.

\section{Larval parasitism in Morocco}

Larval parasitism in Morocco was assessed from a sample of 204 larvae, 87 corresponding to the late winter generation migrating northward upon adult emergence, and 117 to the progeny of European migrants arriving in Morocco in early autumn (Table 3b). Some larvae died for unknown reasons in the laboratory, thus reducing effective sample sizes to 65 and 106 larvae in these two groups, respectively. In total, six primary parasitoid species were recorded, five larval and one larval-pupal (Fig. 1). Four species were found only once (one unidentified Ichneumonidae: Campopleginae, one unidentified Braconidae: Microgastrinae [in both cases the adults failed to emerge], and a single $D$. sicaria) or twice ( $S$. bella, at a relatively humid mountain site), and are probably unusual parasitoids of $V$. cardui in this region.

Striking seasonal differences in percentage larval parasitism occurred in Morocco, just as in Spain. By the end of winter, percentage parasitism was five times higher than in autumn $(66.2 \%$ vs. $13.2 \%$ in samples $)$. This was mainly a consequence of the much higher impact of parasitism by $C$. vanessae, which killed more than half of the larvae in the first period, but appeared only very rarely in the subsequent autumn (Fig. 2, Table 3b).

\section{Pupal parasitism in Morocco}

All 50 pupae collected at the mass emergence site in late winter produced either adult butterflies or the gregarious chalcidoid parasitoid Pteromalus puparum (Fig. 1). We have no data on pupal parasitism through the sea- 

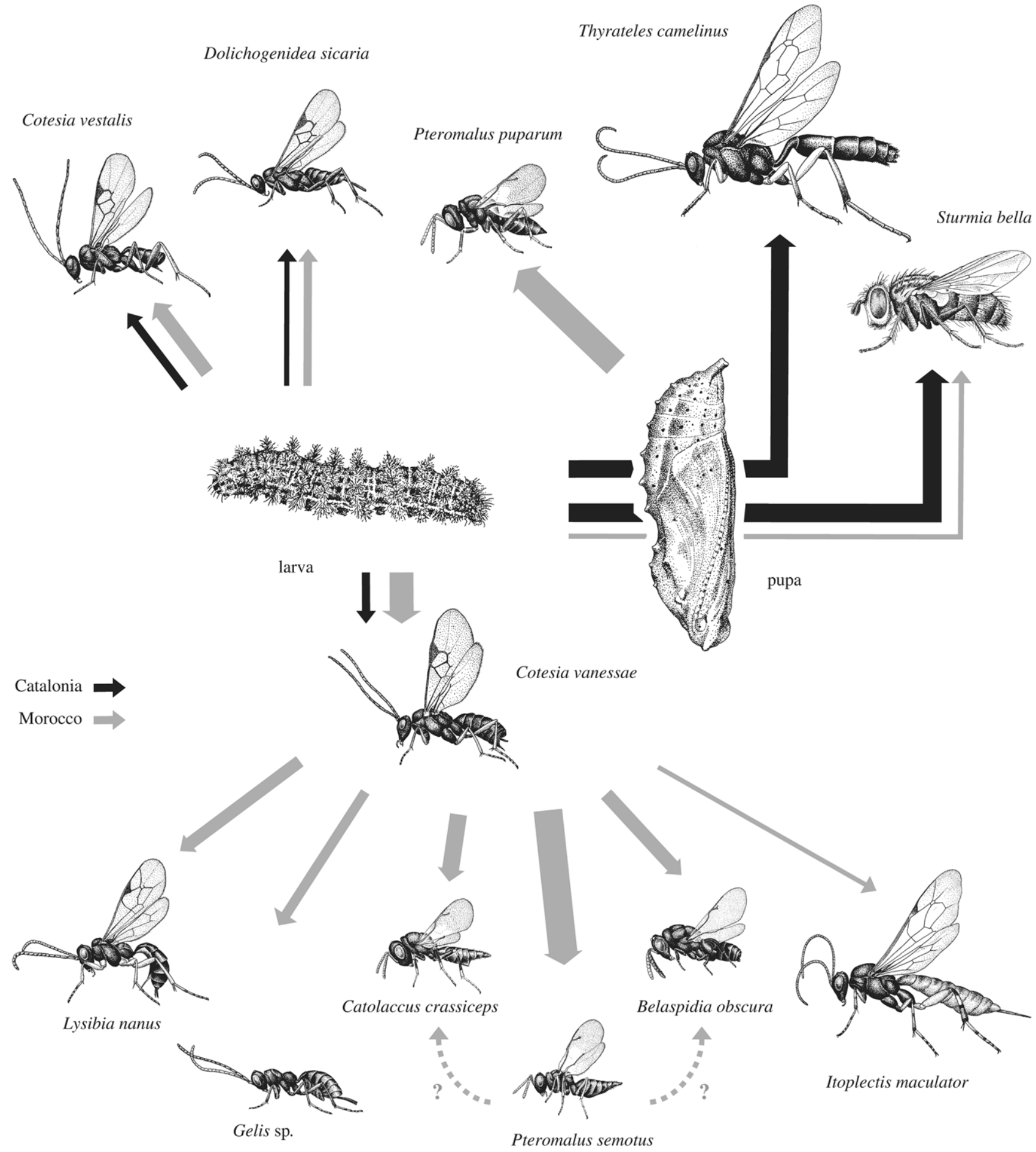

Fig. 1. The parasitoid complex associated with Vanessa cardui in north-east Spain and Morocco in 2009. Occasional parasitoids (i.e. three species that were recorded only once in our samples) are not shown. Thickness of the arrows is proportional to the percentage parasitism recorded in the samples. Bent arrows for Thyrateles camelinus and Sturmia bella indicate that both these species are larval-pupal parasitoids (i.e. the host is killed at the pupal stage but is attacked at the larval stage). Broken arrows with question marks indicate that Belaspidia obscura and Catolaccus crassiceps may have been parasitoids of Pteromalus semotus in some cases (i.e. tertiary parasitoids). All individuals illustrated are females except for Belaspidia obscura, which is a male. The insect illustrations are not presented to scale. Drawing by Jordi Corbera.

son. However, percentage pupal parasitism (34\%) found at the mass emergence site is probably a considerable overestimation because our collection included mostly late pupae (i.e. most of the pupae at the site had already produced adult butterflies), which would include a disproportionately high number infested by the later developing parasitoids. 
TABLE 3. Number of larvae of Vanessa cardui that were collected at different sites in (A) north-east Spain and (B) Morocco, with recorded incidence of parasitoids. Abbreviations: L2-L5 - larval instars, Sb - Sturmia bella, Es - Exorista segregata, Tc - Thyrateles camelinus, Cva - Cotesia vanessae, Cve - Cotesia vestalis, Ds - Dolichogenidea sicarius, Casp - unidentified Campopleginae, Msp - unidentified Microgastrinae, Unk. - dead from unknown causes.

\begin{tabular}{|c|c|c|c|c|c|c|c|c|c|c|c|c|c|c|}
\hline \multicolumn{15}{|c|}{ (A) North-East Spain } \\
\hline & \multicolumn{4}{|c|}{ Number of larvae } & \multirow{2}{*}{ Total } & \multirow{2}{*}{ Adults } & \multicolumn{7}{|c|}{ Causes of mortality } & \multirow{2}{*}{$\begin{array}{c}\text { Total } \\
\text { parasitoids }\end{array}$} \\
\hline & $\mathrm{L} 2$ & L3 & $\mathrm{L} 4$ & L5 & & & $\mathrm{Sb}$ & Es & $\mathrm{Tc}$ & Cva & Cve & Ds & Unk & \\
\hline \multicolumn{15}{|l|}{ Spring } \\
\hline Sorteny & & & & 2 & 2 & 0 & & & 2 & & & & & 2 \\
\hline S Celoni & & & 6 & 6 & 12 & 10 & & & & & & & 2 & 0 \\
\hline S P Vilamajor_1 & 5 & 13 & 18 & 15 & 51 & 37 & 1 & & 1 & & & & 12 & 2 \\
\hline S P Vilamajor_2 & & & 26 & 37 & 63 & 44 & 7 & 1 & 8 & & & & 3 & 16 \\
\hline Total & 5 & 13 & 50 & 60 & 128 & 91 & 8 & 1 & 11 & 0 & 0 & 0 & 17 & 20 \\
\hline$\%$ parasitism & & & & & & & 7.2 & 0.9 & 9.9 & 0 & 0 & 0 & & 18.0 \\
\hline \multicolumn{15}{|l|}{ Late summer } \\
\hline Marialles & & & & 1 & 1 & 0 & & & 1 & & & & & 1 \\
\hline Peña Telera & & & & 4 & 4 & 1 & 1 & & 1 & 1 & & & & 3 \\
\hline Nevà & & & & 4 & 4 & 3 & 1 & & & & & & & 1 \\
\hline S A Vilamajor & & & & 2 & 2 & 0 & & & & 2 & & & & 2 \\
\hline S P Vilamajor_1 & 5 & 2 & 1 & 2 & 10 & 1 & 6 & & & & 1 & 1 & 1 & 8 \\
\hline S P Vilamajor_2 & 2 & & & & 2 & 0 & & & & & 1 & 1 & & 2 \\
\hline Total & 7 & 2 & 1 & 13 & 23 & 5 & 8 & 0 & 2 & 3 & 2 & 2 & 1 & 17 \\
\hline$\%$ parasitism & & & & & & & 36.4 & 0 & 9.1 & 13.6 & 9.1 & 9.1 & & 77.3 \\
\hline \multicolumn{15}{|l|}{ (B) Morocco } \\
\hline & \multicolumn{4}{|c|}{ Number of larvae } & Total & Adults & \multicolumn{7}{|c|}{ Causes of mortality } & Total \\
\hline & $\mathrm{L} 2$ & L3 & $\mathrm{L} 4$ & L5 & Iotal & Aduits & Sb Casp & Cva & Cve & Ds & Msp & $\mathrm{Pp}$ & Unk & parasitoids \\
\hline
\end{tabular}

\begin{tabular}{|c|c|c|c|c|c|c|c|c|c|c|c|c|c|c|c|}
\hline \multicolumn{16}{|l|}{ Late winter } \\
\hline P9 & & & 2 & 1 & 3 & & & & 3 & & & & & & 3 \\
\hline $\mathrm{P} 10$ & & & & 2 & 2 & & & & 2 & & & & & & 2 \\
\hline P11 & & 2 & 2 & 1 & 5 & & & & 4 & & & & & 1 & 4 \\
\hline P13 & 2 & & & & 2 & 1 & & & 1 & & & & & & 1 \\
\hline $\mathrm{P} 14$ & & 5 & 6 & & 11 & 7 & & & 2 & & & & & 2 & 2 \\
\hline P15 & & & 11 & 11 & 22 & 4 & & 1 & 14 & & & 1 & & 2 & 16 \\
\hline P16 & & 1 & & & 1 & & & & & & & & & 1 & 0 \\
\hline $\mathrm{P} 20$ & & & 14 & & 14 & 2 & & & 4 & 1 & & & & 7 & 5 \\
\hline $\mathrm{P} 22$ & & & 2 & & 2 & & & & 2 & & & & & & 2 \\
\hline $\mathrm{P} 23$ & & & 1 & & 1 & & & & & & & & & 1 & 0 \\
\hline $\mathrm{P} 24$ & & & & & 0 & 33 & & & & & & & 17 & & 17 \\
\hline P27 & & & 6 & & 6 & & & & 3 & & & & & 3 & 3 \\
\hline P28 & & 2 & 5 & & 7 & 5 & & & 1 & & & & & 1 & 1 \\
\hline P34 & & & & 11 & 11 & 3 & & & 4 & & & & & 4 & 4 \\
\hline Total & 2 & 10 & 49 & 26 & 87 & 55 & 0 & 1 & 40 & 1 & 0 & 1 & 17 & 22 & 60 \\
\hline$\%$ parasitism & & & & & & & 0 & 1.5 & 61.5 & 1.5 & 0 & 1.5 & 34 & & 66.2 \\
\hline
\end{tabular}

Autumn

\begin{tabular}{|c|c|c|c|c|c|c|c|c|c|c|c|c|c|c|c|}
\hline P0_1 & 1 & & & & 1 & & & & & 1 & & & & & 1 \\
\hline $\mathrm{PO}_{-} 2$ & & & & 7 & 7 & 6 & & & & & & & & 1 & 0 \\
\hline P1_1 & 17 & & & 4 & 21 & 16 & & & & 5 & & & & & 5 \\
\hline P1_2 & 14 & 2 & 3 & 2 & 21 & 18 & & & 2 & & & & & 1 & 2 \\
\hline $\mathrm{P} 2$ & 2 & 7 & & & 9 & 9 & & & & & & & & & 0 \\
\hline P3 & & 1 & & & 1 & & & & & & 1 & & & & 1 \\
\hline P5 & & 2 & & 2 & 4 & 4 & & & & & & & & & 0 \\
\hline P7 & 3 & 1 & 1 & & 5 & 4 & & & & & & & & 1 & 0 \\
\hline P11 & & & 4 & 3 & 7 & 4 & & & & & & & & 3 & 0 \\
\hline P15 & 6 & & & & 6 & 4 & 2 & & & & & & & & 2 \\
\hline P17 & 15 & 10 & 4 & 1 & 30 & 24 & & & & 3 & & & & 3 & 3 \\
\hline P18 & & & & 5 & 5 & 3 & & & & & & & & 2 & 0 \\
\hline Total & 58 & 23 & 12 & 24 & 117 & 92 & 2 & 0 & 2 & 9 & 1 & 0 & 0 & 11 & 14 \\
\hline$\%$ parasitism & & & & & & & 1.9 & 0 & 1.9 & 8.5 & 0.9 & 0 & 0 & & 13.2 \\
\hline
\end{tabular}



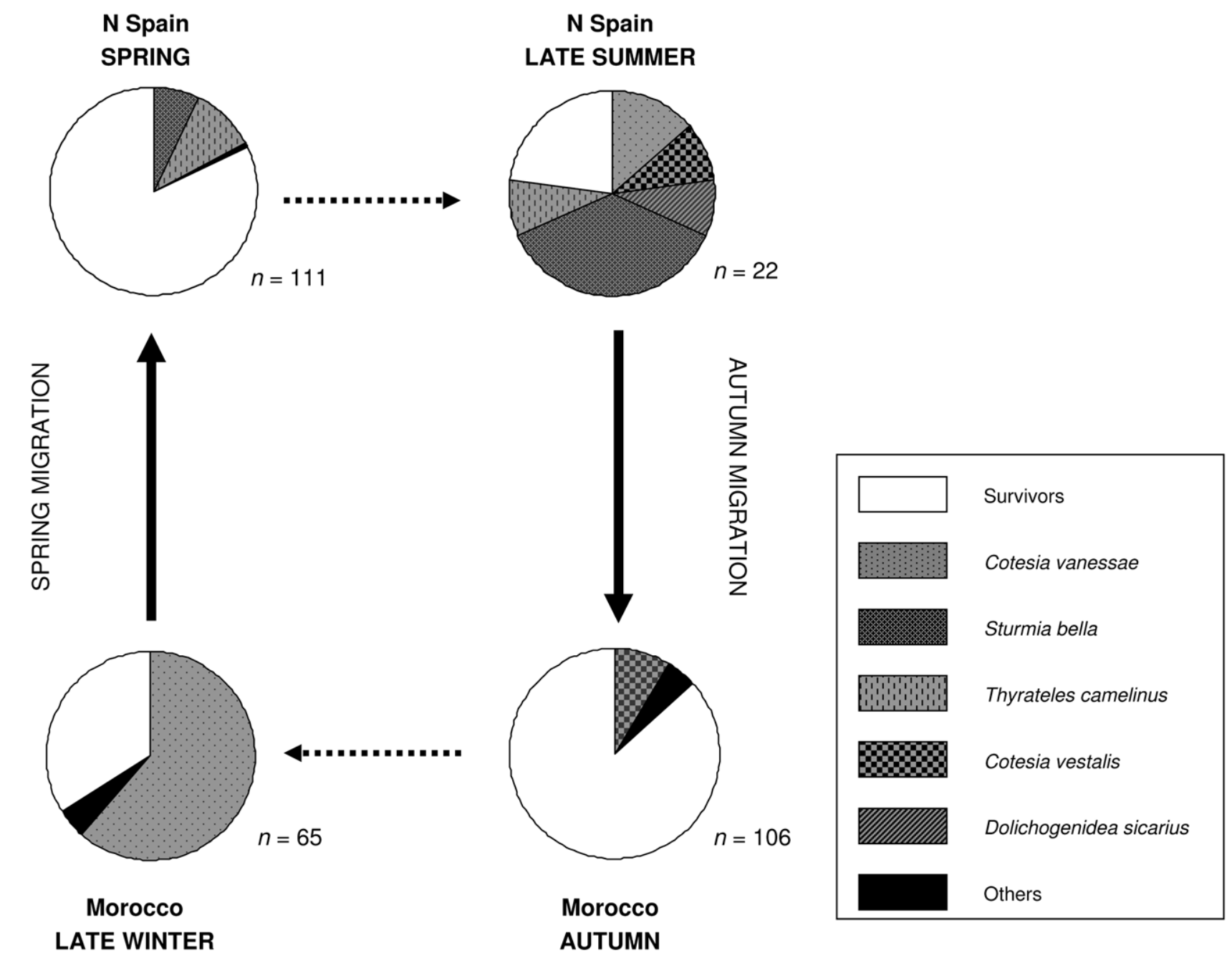

Fig. 2. Schematic representation of the structure and temporal variability in the parasitoid complexes of Vanessa cardui in Morocco and north-east Spain, showing the potential importance of enemy-free space as a selective force favouring long-distance seasonal migration in this butterfly.

\section{Biology of the primary parasitoids}

Basic data on the biology of the more common primary parasitoids is summarized in Table 4 (see also Shaw et al., 2009). All species are endoparasitoid koinobionts, except $P$. puparum which is an idiobiont.

The sex ratio of $P$. puparum was strongly female biased (binomial test, $P<0.001$; Table 4), but Moroccan $C$. vanessae broods consisted exclusively of females, confirming that southern populations of this species are thelytokous (Shaw et al., 2009, M.R. Shaw, unpubl. data from the Canary Islands and Crete). No males were reared from the few broods of $C$. vanessae from northeast Spain, but this is unequivocal as emergence was incomplete and broods received from another part of Spain (Córdoba, R.O. Romero leg.) in 2009 did contain males, as is usual in more northern populations. There was an approximately even sex ratio in the other species (Table 4).

\section{Secondary parasitism of Cotesia vanessae}

Six species were recorded as pseudohyperparasitoids, attacking C. vanessae after it had left the body of the host and formed cocoons (Fig. 1, Table 5). Pteromalus semotus was the commonest secondary parasitoid, occurring in nearly half of the cocoon clusters at the mass outbreak site, and it was also present at the other two sites from where cocoon clusters of $C$. vanessae were collected. Four other species (Catolaccus crassiceps, Belaspidia obscura, Lysibia nanus and Itoplectis maculator) were much rarer at $\mathrm{P} 24$, occurring in $1-10 \%$ of the cocoon clusters. Gelis sp. was found at a single site (P31), where it seemed to have a high incidence (it was present in 3 out of 8 cocoon clusters collected). The relatively high frequency of $C$. crassiceps and B. obscura in cocoon clusters of $C$. vanessae with P. semotus $(0.60$ and 0.67 , respectively), together with their small size, suggest that they might in some cases have been parasitoids of the latter species (that is, tertiary parasitoids).

\section{DISCUSSION}

\section{The structure of the parasitoid complexes of Vanessa} cardui

In the western Palaearctic, parasitoids have been reported from all immature stages of the painted lady. We 
TABLE 4. Biological data for the regular species of primary parasitoids of Vanessa cardui. Host use follows that described in Shaw et al. (2009). " $n$ " refers to the number of parasitized hosts.

\begin{tabular}{|c|c|c|c|c|c|c|}
\hline \multirow{2}{*}{ Parasitoid } & \multirow{2}{*}{ Host stage attacked } & \multirow{2}{*}{$\begin{array}{l}\text { Stage at which } \\
\text { the host is killed }\end{array}$} & \multicolumn{2}{|c|}{ No. parasitoids/host } & \multirow{2}{*}{$\begin{array}{l}\text { Sex ratio } \\
\mathrm{m} / \mathrm{f}\end{array}$} & \multirow{2}{*}{ Host use } \\
\hline & & & Mean \pm SD & $\mathrm{n}$ & & \\
\hline Thyrateles camelinus & Late instar larva & Pupa & $1 \pm 0$ & 10 & $3 / 7$ & Nymphalini \\
\hline Cotesia vanessae & Early instar larva & 5th instar larva & $40.6 \pm 25.5$ & 31 & $1 / 2173$ & Nymphalini, Noctuidae \\
\hline Cotesia vestalis & Early instar larva & 2-3rd instar larva & $1 \pm 0$ & 11 & $4 / 5$ & $\begin{array}{l}\text { Nymphalini, Satyrinae, } \\
\text { other Lepidoptera }\end{array}$ \\
\hline Dolichogenidea sicarius & Early instar larva & 2-3rd instar larva & $1 \pm 0$ & 2 & $1 / 1$ & Broad (seldom butterflies) \\
\hline Pteromalus puparum & Pupa & Pupa & $48.1 \pm 31.3$ & 17 & $166 / 651$ & $\begin{array}{c}\text { Butterflies, especially Papilionidae, } \\
\text { Pierinae and Nymphalini }\end{array}$ \\
\hline Sturmia bella & Larvae of any instar & Pupa & $1.5 \pm 0.7$ & 18 & $14 / 10$ & Mainly Nymphalini \\
\hline
\end{tabular}

did not sample egg parasitoids, although various species of Chalcidoidea Trichogrammatidae (Trichogramma bourarachae Pintureau \& Barbault, 1988, T. euproctidis (Girault, 1911), T. voegelei Pintureau, 1990, T. minutum Riley, 1871, Trichogrammatoidea lutea (Girault, 1911)) and two of Platygastroidea Scelionidae (Telenomus laeviceps Foerster, 1861, and T. punctatissimus (Ratzeburg, 1844)) are recorded from Europe and Morocco (Rohi \& Pintureau, 2003; Noyes, 2009; B. Pintureau, pers. comm.) and may be an important component of the parasitoid complexes of $V$. cardui under some circumstances.

As for larval and pupal parasitoids, five out of six species reported by Shaw et al. (2009) attacking $V$. cardui in Europe (T. camelinus, C. vanessae, C. vestalis, D. sicaria and $P$. puparum) were recorded in our study. The only species absent from our samples, Microgaster subcompleta Nees, 1834, is mainly a parasitoid of the butterfly Vanessa atalanta (Linnaeus, 1758) and the pyralid moth Pleuroptya ruralis (Scopoli, 1763), both feeding on Urtica, and it may use $V$. cardui only as an infrequent host (Shaw et al., 2009). Likewise, the three species that we found that were not included in the work by Shaw et al. (2009) were recorded only once and can be regarded as occasional parasitoids. The same applies to a few other broad generalist Chalcidoidea that are occasionally mentioned as larval or pupal parasitoids in the literature (e.g. the eulophid Elasmus nudus (Nees, 1834) and the chalcidid Brachymeria femorata (Panzer, 1801): Labeyrie, 1962; Noyes, 2009).
None of the species of primary parasitoids is a strict specialist on $V$. cardui, but $T$. camelinus seems to use exclusively butterfly hosts in the tribe Nymphalini, and $S$. bella, although sometimes using other hosts, is very strongly associated with this tribe. Cotesia vanessae also shows a strong preference for Nymphalini but, at least in some areas, alternates with other hosts (a probably limited range of low-feeding moths in the family Noctuidae; cf. Nixon, 1974) when the former are seasonally unavailable (Shaw et al., 2009). Cotesia vestalis is known to attack a broad range of Nymphalini and Satyrinae butterflies, as well as the diamondback moth Plutella xylostella (Linnaeus, 1758) (Lepidoptera: Plutellidae), a cosmopolitan and economically important host. Pteromalus puparum is known from a wide range of butterflies, particularly Nymphalidae, Papilionidae and Pieridae, while D. sicaria is a niche-specialist parasitizing hosts in several Lepidoptera families that are small and concealed within prominent field layer plants.

Available data thus seem to indicate that (larval) parasitoid complexes of $V$. cardui are rather simple throughout the western Palaearctic, consisting mainly of a few koinobionts relatively specialized on nymphalid butterflies in the tribe Nymphalini (Table 4). The relative impoverishment of the Moroccan parasitoid assemblages, mostly consisting of $C$. vanessae by the end of winter and $C$. vestalis in early autumn (Fig. 2), is probably due to the hostility of an increasingly arid environment, as noted more generally by Hawkins (1990) when affirming that parasitoid richness tends to be lower in deserts.

TABLE 5. Species of secondary parasitoids recorded from 159 cocoon masses of Cotesia vanessae collected at three sites in Morocco. One hundred cocoon masses from site P24, 8 from site P31 and 1 from site P15 were reared individually and used to estimate the incidence of parasitism of cocoon masses of $C$. vanessae.

\begin{tabular}{lcccccc}
\hline Species & Indiv. & $\begin{array}{c}\text { Sex ratio } \\
\mathrm{m} / \mathrm{f}\end{array}$ & $\begin{array}{c}\text { \% cocoon masses } \\
\text { attacked }\end{array}$ & $\begin{array}{c}\text { Mean number emerging/ } \\
\text { cocoon mass } \pm \text { SD }\end{array}$ & $\begin{array}{c}\text { Other species in same cocoon mass } \\
\text { (occurrences/possibilities) }\end{array}$ \\
\hline Belaspidia obscura & 9 & $7 / 2$ & 5.5 & $1.5 \pm 0.8$ & Pteromalus semotus \\
Itoplectis maculator & 2 & $2 / 0$ & 0.9 & $1 \pm 0$ & Pteromalus semotus \\
Gelis sp. & 10 & $8 / 2$ & 2.8 & $3.3 \pm 0.6$ & Pteromalus semotus & $2 / 3$ \\
Lysibia nanus & 139 & $55 / 84$ & 4.6 & $14.8 \pm 7.2$ & Pteromalus semotus & $2 / 5$ \\
Catolaccus crassiceps & 56 & $19 / 37$ & 9.2 & $5.6 \pm 4.1$ & Pteromalus semotus & $6 / 10$ \\
Pteromalus semotus & 460 & $213 / 247$ & 48.6 & $7.8 \pm 6.2$ & Belaspidia obscura & $4 / 53$ \\
& & & & & Itoplectis maculator & $1 / 53$ \\
& & & & & Gelis sp. & $2 / 53$ \\
& & & & Lysibia nanus & $2 / 53$ \\
& & & & & Catolaccus crassiceps & $6 / 53$ \\
\hline
\end{tabular}


Cotesia vanessae in both North Africa and Europe, and $T$. camelinus and $S$. bella in Europe, can thus be considered as the key species that drive most of the larval hostparasitoid interactions in this system. Undoubtedly, parasitism by these three species represents a regular and important mortality factor in the host populations. While Pteromalus puparum may at times be important, additional broad generalists are rare or occasional, probably contributing very little to overall mortality. This general pattern fits very well with that described by Hawkins (1994: pp. 125-130) in his monograph on host-parasitoid interactions.

\section{The impact of secondary parasitism on Cotesia vanessae}

The incidence of secondary parasitism on $C$. vanessae was quantitatively assessed at the mass emergence site. Approximately half of the cocoon clusters of $C$. vanessae (54\%) were attacked by several species of pseudohyperparasitoids (mainly $P$. semotus), although only a fraction $(10-50 \%)$ of the cocoons within a single affected cluster were killed (cf. Table 5). Thus, although secondary parasitism certainly reduced the population of $C$. vanessae by a significant amount, there still would be many successful emergences of the primary parasitoid. Stefanescu et al. (2011) estimated, without correcting for secondary parasitism, that nearly $600,000 C$. vanessae could have emerged from this site. If we take secondary parasitism into account, the final figure could be estimated at around 450,000-570,000 (i.e. 300,000 unaffected cocoon clusters $+50 \%$ of 300,000 affected cocoon clusters to 300,000 unaffected cocoon clusters $+90 \%$ of 300,000 affected cocoon clusters). In this respect, our data suggest that the impact of parasitism on $C$. vanessae is much lower than on other related species with more northern distributions (e.g. van Nouhuys \& Tay, 2001; Harvey et al., 2009; Stefanescu et al., 2009). However, further data for a range of host densities and from several years are required before the role of secondary parasitism in the parasitoid complex of $V$. cardui can be fully appreciated.

With the exception of B. obscura (and possibly the Gelis sp.), the secondary parasitoids recorded in this study are widespread generalist species, attacking a broad range of hosts. Pteromalus semotus is an ectoparasitoid, usually solitary, and a primary parasitoid of smaller Lepidoptera (e.g. Coleophoridae, Yponomeutidae) and Coleoptera (Bruchidae and Curculionidae) or, more usually, a pseudohyperparasitoid of Lepidoptera through a braconid primary parasitoid (Blunck, 1944; Delucchi \& Verbeke, 1953; Graham, 1969; Askew et al., 2001). Catolaccus crassiceps is another polyphagous chalcidoid that is mainly known as a solitary ectoparasitoid in microgastrine cocoons, but is also recorded as a primary parasitoid of Lepidoptera (Gelechiidae, Noctuidae, Pieridae and Pyralidae), Pseudococcidae (Hemiptera), Curculionidae (Coleoptera) and Chrysopidae (Neuroptera) (Noyes, 2009). It has a broad southern Palaearctic distribution, not extending as far north as P. semotus in Europe. Itoplectis maculator is generally abundant both as a primary parasitoid of the pupae of small to medium sized Lepidoptera (e.g. Tortricidae) and also as a pseudohyperparasitoid attacking ichneumonoid cocoons, but it rarely uses hosts as small as Cotesia (Fitton et al., 1988) and it is significant that the two specimens reared here were both males. The Gelis sp. is near G. seyrigi Ceballos, 1925, but not certainly determined. This genus includes many species that make frequent use of microgastrine cocoons (Schwarz \& Shaw, 1999). Lysibia nanus is an abundant parasitoid of exposed gregarious microgastrine cocoons, regularly using those of Cotesia species (Schwarz \& Shaw, 2000). Belaspidia obscura does not appear to have been previously reported as a secondary parasitoid. It has a southern Palaearctic range and is best known as a primary parasitoid of a number of species of Apterona, Cochliotheca and Rebellia (Lepidoptera: Psychidae).

\section{The adaptative value of migration to avoid parasitism}

A striking pattern that emerged from our study was the considerable seasonal variation in parasitism of the host populations (Fig. 2). When the butterflies arrived and started to breed in areas from which they had been absent for several months, overall parasitism was always low. This contrasts with the situation immediately preceding their emigration from the same areas some months later, with typically very high parasitism loads. The incidence of $C$. vanessae in Morocco clearly exemplifies this pattern. By the end of winter it was extremely abundant, being reared from more than half of the larvae collected; on the other hand, it was very rare in larvae developing in the same region seven months later, soon after the butterfly returned to Morocco in autumn (see also Owen, 1989; Owen \& Wiemers, 1992). This is probably the consequence of low survival of the parasitoid when the host becomes unavailable between spring and autumn, leading to a population crash because of the shortage of hosts. Then $C$. vanessae numbers would, from an extremely low base, be able to progressively build up in the successive local generations of $V$. cardui occurring between autumn and winter, resulting in the usual pattern of increasing parasitism in multivoltine hosts as the season progresses (e.g. Dempster, 1984; Askew \& Shaw, 1986).

We suggest that the build up of parasitoid populations when $V$. cardui breeds in the same general area in successive generations, and the benefit of enemy-free space, could potentially have favoured a strategy of seasonal long-distance migration in this butterfly. Berdegue et al. (1996) identified three hypothesis to be tested sequentially in order to show the importance of enemy-free space. Although further data from different years will be needed for a rigorous test, the available empirical evidence provided by this study supports the first two requirements: (1) that the fitness of $V$. cardui in the presence of its natural enemies is less than in their absence, as deduced from the high level of larval mortality that the main parasitoids inflicted on the host populations; and (2) that the fitness in the alternative habitat with natural enemies (i.e. the areas that are colonized through migration) is greater than in the original habitat with natural enemies (Fig. 2). 
The third requirement, that the fitness in the alternative habitat without natural enemies is lower than in the original habitat without natural enemies, certainly does not hold in the medium term, as the environmental conditions in the original habitats suffer a predictable deterioration at the same time as the new habitats become increasingly favourable. However, it should be noted that even this requirement may apply in the short term, because the environmental conditions in the original habitats (e.g. the thermal conditions and the availability of feeding resources) may still be better than in the alternative habitats when long-distance migrations start. In any case, as pointed out by Berdegue et al. (1996), the failure of the third requirement would simply indicate that other factors have also been important in shaping the seasonal migratory behaviour in $V$. cardui. In particular, it seems that seasonal movements have mainly evolved to allow exploitation of ephemeral resources that become available in spring and summer in the temperate region, and in autumn and winter in the subtropical region. While migration rather than diapause is clearly an evolved strategy in $V$. cardui to deal with seasonal resource failure, escape from parasitism might well have played an important part in promoting that strategy.

ACKNOWLEDGEMENTS. Tachinids were kindly identified by H.-P. Tschorsnig. A. Àvila, R. Izquierdo, F. Páramo and E. Sylvestre helped with the field work. M. Schwarz commented on the Gelis species. Thanks are due to R. Obregón for sharing his data and to M. Miralles for helful discussions. Two anonymous reviewers made helpful comments on the original MS. The Moroccan expedition was supported financially by grants CSD2008-00040 (Consolider Ingenio MONTES) and CGL2009 $-13188-\mathrm{C} 03-01$.

\section{REFERENCES}

ACKeRY P.R. 1988: Hostplants and classification: a review of nymphalid butterflies. Biol. J. Linn. Soc. 33: 95-203.

Asher J., Warren M., Fox R., Harding P., Jeffcoate G. \& JeffCOATE S. 2001: The Millennium Atlas of Butterflies in Britain and Ireland. Oxford University Press, Oxford, $433 \mathrm{pp}$.

Askew R.R. \& Shaw M.R. 1986: Parasitoid communities: their size, structure and development. In Waage J. \& Greathead D. (eds): Insect Parasitoids. Academic Press, London, pp. 225-264.

Askew R.R., Blasco-Zumeta J. \& Pujade-Villar J. 2001: Chalcidoidea y Mymarommatoidea (Hymenoptera) de un sabinar de Juniperus thurifera L. en los Monegros, Zaragoza. Monografías SEA, Vol. 4. Sociedad Entomológica Aragonesa, Zaragoza, $76 \mathrm{pp}$

Berdegue M., Trumble J.T., Hare J.D. \& Redak R.A. 1996: Is it enemy-free space? The evidence for terrestrial insects and freshwater arthropods. Ecol. Entomol. 21: 203-217.

BluncK H. 1944: Zur Kenntnis der Hyperparasiten von Pieris brassicae L. Z. Angew. Entomol. 30: 418-491.

Delucchi V. \& VerbeKe J. 1953: Habrocytus milleri n. sp., ectoparasite de Coleophora frischella L. Bull. Inst. R. Sci. Nat. Belg. Entomol. 29: 1-14.

Dempster J.P. 1984: The natural enemies of butterflies. In VaneWright R.I. \& Ackery P.R. (eds): The Biology of Butterflies. Academic Press, London, pp. 97-104.
Fitton M.G., Shaw M.R. \& Gauld I.D. 1988: Pimplinae Ichneumon-flies. Hymenoptera Ichneumonidae (Pimplinae). Handb. Ident. Br. Insects 7(1): 1-110.

Fox R. 2010: 2009: The year of the Painted Lady. Atropos 40: $3-14$.

Graham M.W.R. DE V. 1969: The Pteromalidae of northwestern Europe (Hymenoptera: Chalcidoidea). Bull. Br. Mus. Nat. Hist. (Entomol.) Suppl. 16: 1-908.

Hammad S.M. \& RaAfat A.M. 1972: The biology of the painted lady butterfly, Vanessa (Pyrameis) cardui L. (Lepidoptera: Nymphalidae). Bull. Soc. Entomol. Egypte 56: 15-20.

Harvey J.A., WagenaAr R. \& Bezemer T.M. 2009: Interactions to the fifth trophic level: secondary and tertiary parasitoid wasps show extraordinary efficiency in utilizing host resources. J. Anim. Ecol. 78: 686-692.

Hawkins B.A. 1990: Global patterns of parasitoid assemblage size. J. Anim. Ecol. 59: 57-72.

Hawkins B.A. 1994: Pattern and Process in Host-Parasitoid Interactions. Cambridge University Press, Cambridge, 190 pp.

JefFries M.J. \& Lawton J.H. 1984: Enemy free space and the structure of ecological communities. Biol. J. Linn. Soc. 23: 269-286.

LABEYRIE V. 1962: On some Hymenoptera intervening in the biocoenosis of pests on artichoke in the south-east of France. Entomophaga 6: 249-256.

NiXon G.E.J. 1974: A revision of the north-western European species of the glomeratus-group of Apanteles Förster (Hymenoptera, Braconidae). Bull. Entomol. Res. 64: 453-524.

NoYES J.S. 2009: Universal Chalcidoidea Database. The Natural History Museum, London. Available from: http://www.nhm. ac.uk/research-curation/projects/chalcidoids. Consulted 22.vii.2010.

OwEn D.F. 1987: Winter breeding by Cynthia cardui (L.) (Lepidoptera: Nymphalidae) in Crete and Madeira, and the possible significance of parasitoids in initiating migration. Entomol. Gaz. 38: 11-12.

Owen D.F. 1989: Possible origin of the migratory Cynthia cardui L. (Lep.: Nymphalidae). Entomol. Rec. J. Variat. 101: $51-52$.

Owen D.F. \& Wiemers M. 1992: The butterflies of Fuerteventura. Entomol. Gaz. 43: 87-92.

Pollard E., van Swahy C.A.M., Stefanescu C., Lundsten K.E., Maes D. \& Greatorex-Davies J.N. 1998: Migration of the painted lady butterfly Cynthia cardui in Europe: evidence from monitoring. Divers. Distrib. 4: 243-253.

Rohi L. \& Pintureau B. 2003: Are Trichogramma bourarachae and the perkinsi species group really distinct from Trichogramma buesi and the pintoi group, respectively? J. Appl. Entomol. 127: 265-268.

Schwarz M. \& SHaw M.R. 1999: Western Palaearctic Cryptinae (Hymenoptera: Ichneumonidae) in the National Museums of Scotland, with nomenclatural changes, taxonomic notes, rearing records and special reference to the British check list. Part 2. Genus Gelis Thunberg (Phygadeuontini: Gelina). Entomol. Gaz. 50: 117-142.

Schwarz M. \& Shaw M.R. 2000: Western Palaearctic Cryptinae (Hymenoptera: Ichneumonidae) in the National Museums of Scotland, with nomenclatural changes, taxonomic notes, rearing records and special reference to the British check list. Part 3. Tribe Phygadeuontini, subtribes Chiroticina, Acrolytina, Hemitelina and Gelina (excluding Gelis), with descriptions of new species. Entomol. Gaz. 51: 147-186.

Shaw M.R., Stefanescu C. \& van Nouhuys S. 2009: Parasitism of European butterflies (Hesperioidea and Papilionoidea). In Settele J., Shreeve T.G., Konvicka M. \& van Dyck H. (eds): 
Ecology of Butterflies in Europe. Cambridge University Press, Cambridge, pp. 130-156

ShIELDS O. 1992: World distribution of the Vanessa cardui group (Nymphalidae). J. Lepid. Soc. 46: 235-238.

StefanESCU C. 1997: Migration patterns and feeding resources of the Painted Lady butterfly, Cynthia cardui (L.) (Lepidoptera, Nymphalidae) in the northeast of the Iberian peninsula. Misc. Zool. 20: 31-48.

Stefanescu C., Planas J. \& Shaw M.R. 2009: The parasitoid complex attacking coexisting Spanish populations of Euphydryas aurinia and Euphydryas desfontainii (Lepidoptera: Nymphalidae, Melitaeini). J. Nat. Hist. 43: 553-568.

Stefanescu C., Alarcón M., Izquierdo R., Páramo F. \& Àvila A. 2011: Moroccan source areas of the Painted Lady butterfly Vanessa cardui (Nymphalidae: Nymphalinae) migrating into Europe in spring. J. Lepid. Soc. 65: 15-26.

VAN NouhuYS S. \& TAY W.T. 2001: Causes and consequences of small population size for a specialist parasitoid wasp. Oecologia 128: 126-133.
VANDENBOSCH R. 2003: Fluctuations of Vanessa cardui butterfly abundance with El Niño and Pacific Decadal Oscillation climatic variables. Glob. Change Biol. 9: 785-790.

WIEMERS M. 1995: The butterflies of the Canary Islands. A survey on their distribution, biology and ecology (Lepidoptera: Papilionoidea and Hesperioidea) (second part). Linn. Belg. 15: 87-118.

Williams C.B. 1930: The Migration of Butterflies. Oliver \& Boyd, Edinburgh, $473 \mathrm{pp}$.

WiLliams C.B. 1970: The migrations of the Painted Lady butterfly Vanessa cardui (Nymphalidae), with special reference to North America. J. Lepid. Soc. 24: 157-175.

Wiltshire E.P. 1949: The phenological classification of Palaearctic Lepidoptera. A preliminary essay. Entomol. Rec. J. Variat. 53: 101-106.

Received August 25, 2011; revised and accepted October 10, 2011 